\title{
Biases in the study of relationships between biodiversity dynamics and fluctuation of environmental conditions
}

\author{
Stéphane Jouve, Bastien Mennecart, Julien Douteau, and Nour-Eddine Jalil
}

\begin{abstract}
During the last decades, studies testing the correlations between the dynamics of diversity with various environmental variables strongly increased, but numerous biases affecting these analyses have been recognised. Recent studies considering the evolution of marine crocodylomorphs in comparison with the fluctuations of sea surface temperature and sea level found contradictory results. However, we considered a diversity analysis published two years before our work, and noticed several taxonomical issues (new material and species described since the publication of this paper, unidentified thalattosuchians in time bins where previous analyses considered the absence of any marine crocodylomorphs, and some taxonomical corrections). Here we test the impact of updating the dataset on these results. We also tested the consequences of the time range considered and various methods in reconstructing the sea surface temperature curve.

Each of these corrections and modifications impacts strongly the results, and most of them drive to a different conclusion from the original work. These results point out the crucial importance of taxonomical work in diversity studies to provide reliable results, such as the method used to construct the proxies.

The contradictory results obtained here question the reliability of the correlations proposed until now between crocodylomorph evolution and environmental proxies. Deep taxonomic and phylogenetic review should be conducted prior to studying the diversity evolution of a group. This also strongly questions the use of the Paleobiology Database in diversity analyses when the studied group has not yet been reviewed and that numerous, doubtful, nineteenth century species are considered in this dataset.
\end{abstract}

Stéphane Jouve. Sorbonne Universités, UPMC Univ Paris 06, CNRS, Muséum National d'Histoire Naturelle, Centre de Recherche sur la paléobiodiversité et les Paléoenvironnements (CR2P), 4 Place Jussieu, Tour 56, 5ème étage, F-75005, Paris, France jouvestephane@yahoo.fr

Bastien Mennecart. Muséum National d'Histoire Naturelle, CR2P, CNRS-MNHN-UPMC, Département Histoire de la Terre, CP38, 57 rue Cuvier, 75005 Paris, France; Naturhistorisches Museum Basel, Augustinergasse 2, 4001 Basel, Switzerland mennecartbastien@gmail.com Julien Douteau. Le pontet 03160 Franchesse, France, Variraptor@hotmail.fr Nour-Eddine Jalil. Muséum National d'Histoire Naturelle, CR2P, CNRS-MNHN-UPMC, Département

Jouve, Stéphane, Mennecart, Bastien, Douteau, Julien, and Jalil, Nour-Eddine. 2017. Biases in the study of relationships between biodiversity dynamics and fluctuation of environmental conditions. Palaeontologia Electronica 20.1.18A:

$1-21$

palaeo-electronica.org/content/2017/1821-diversity-analysis-biases

Copyright: @ April 2017 Society of Vertebrate Paleontology. This is an open access article distributed under the terms of the Creative Commons Attribution License, which permits unrestricted use, distribution, and reproduction in any medium, provided the original author and source are credited.

creativecommons.org/licenses/by/4.0/ 
Histoire de la Terre, CP38, 57 rue Cuvier, 75005 Paris, France; BioDECOS Laboratory, Faculty of Sciences Semlalia, Universiy Cadi Ayyad, Morocco njalil@mnhn.fr

Keywords: Thalattosuchians; diversity curves; biases; evolution; environmental fluctuations

\section{INTRODUCTION}

It has long been recognised that the fossil record is incomplete and that biases are heterogeneously distributed across time, space, and environment. So, during the last two decades, numerous biases have been identified impacting the study of the biodiversity dynamic: quality of the fossil record (e.g., Benton et al., 2013), variation of the collection effort (e.g., Alroy, 2010a, 2010b), lithologic sampling (Rook et al., 2013), variation in the availability of fossiliferous rocks (e.g., Lloyd et al., 2012), and taxonomic level used (Lloyd et al., 2012). Testing the correlations of the diversity dynamic with every conceivable environmental variable becomes increasingly popular. Several recent works have been conducted studying the evolution of various groups such as ichthyosaurs (Fischer et al., 2016), Triassic marine reptiles (Kelley et al., 2014), marine or terrestrial tetrapods (Benson et al., 2013; Benson and Drunckenmiller, 2014), and more widely, on marine animals (Purdy, 2008). Three analyses tentatively evaluated the evolution of the continental and marine crocodylomorphs according to the evolution of various environmental factors, such as sea level and temperature (Martin et al., 2014; Mannion et al., 2015; Tennant et al., 2016). Martin et al. (2014) focused their study on the marine forms and found significant correlation between generic diversity of the marine non-metriorhynchoid crocodylomorphs and sea surface temperature, whereas Mannion et al. (2015) and Tennant et al. (2016) found support for correlation with sea level change.

Martin et al. (2014), Mannion et al. (2015), and Tennant et al. (2016) studied the crocodylomorphs mainly as a whole; but are they so homogeneous? Since the beginning of the Mesozoic, four crocodylomorph groups dominated the marine realm: crocodylians, some pholidosaurids, Thalattosuchia, and Dyrosauridae (Martin et al., 2014). These latter two groups were almost exclusively marine. If dyrosaurids and crocodylians have been extensively studied and reviewed, it is not the case for a large part of the thalattosuchians, the teleosauroids. The three previously cited works used different sources for this group. Whereas Martin et al. (2014) used species most usually considered as valid, Mannion et al. (2015) and Tennant et al. (2016) used data from the Palaeobiology Database. The introduction of unreviewed groups in the analyses has potential influence on the result, particularly when the concerned group represents nearly one-third of the dataset analysed.

The objective of this paper is to test the impact of several modifications in the datasets on the reliability of the correlations between the marine crocodylomorph diversity with several variations of environmental conditions. We used the recent work proposed by Martin et al. (2014) as a background to test the effect of these modifications in the datasets on the results and conclusions provided in this work.

We tested the introduction of newly described material and species on the analyses, a number of permutations relating to taxonomic level and unidentified crocodylomorphs not included in previous analyses as they were not identified more precisely than being thalattosuchians. These inclusions have consequences on the phylogenetically corrected diversity. Only data from papers available at the beginning of 2016 have been used. Several new species have been described since this date, but in this study we are testing the impact of weak modifications in the dataset on the results, more than the results themselves.

The time interval considered varies according to the analyses. Some studies considered only the time interval with marine crocodylomorphs, whereas others include the stage before and after which did not contain these taxa. As the chosen interval does not seem to be rational, we tested various intervals and their consequences on the results.

The diversity curves are compared with sea level reconstructions (proposed by Haq et al., 1987 and Miller et al., 2005) and with the sea surface temperature curve established from the oxygen isotope composition of fish teeth. Unfortunately, the latter shows a particularly inconsistent sampling, and several other methods of reconstruction have also been tested herein.

Martin et al. (2014) found a correlation between the evolution of the marine crocodylo- 
morphs and the sea surface temperature only when excluding a part of the thalattosuchians. The thalattosuchians are known from the Lower Jurassic (Sinemurian) to the beginning of the Cretaceous (Hauterivian) and are traditionally divided into two groups: the near-shore teleosauroids and the fully marine metriorhynchoids (see Young et al., 2010). Martin et al. (2014) suggested that the evolution of the metriorhynchoids differs from that of other crocodylomorphs and concluded that they could have had a unique ecology. Consequently, we also test the relationships of the teleosauroids' diversity through time with sea surface temperature and sea level. This also allows comparing the results obtained between a wide scale study including all marine crocodylomorphs and only a subset of this group.

\section{MATERIALS AND METHODS}

\section{New Material and Species}

Since the Martin et al. (2014) paper, new material and species with potential impact on the diversity curves, and particularly on their phylogenetically corrected versions, have been published. New teleosauroid material has been described as a snout of "Steneosaurus" obtusidens from the lower Oxfordian of England, whereas this species was previously unknown in this stratigraphic level (Foffa et al., 2015). Previously known from the Callovian to Middle Tithonian, new specimen of blunt-toothed teleosauroids, Machimosaurini (a new Machimosaurus species from the Hauterivian of Tunisia (Fanti et al., 2016) and new specimen of a blunt-toothed teleosauroid from the early Bathonian of Morocco (Jouve et al., 2016)) widely extends the stratigraphic range of these teleosauroids. All have strong consequences on the stratigraphy of blunt-toothed thalattosuchians and the presence of ghost lineages (Appendices 1, 2; Jouve et al., 2016). Lastly, a new dyrosaurid genus and species, Anthracosuchus balrogus, from the Palaeocene of Colombia (Hastings et al., 2015), increases the number of taxa for this family during the Palaeocene. We thus tested the impact of the addition of these taxa on the statistical results obtained for the correlation between crocodylomorph diversity, sea surface temperature, and sea level.

\section{Unidentifed Thalattosuchians and Ghost Lineages}

No Sinemurian to Pliensbachian crocodylomorphs species are included in the analysis of
Martin et al. (2014), but thalattosuchians remains are known in this stratigraphic interval (see Bardet et al., 2014). Even poorly preserved and not identified at the generic or specific level, these remains attest that some marine crocodylomorphs (probably teleosauroids) were present during this interval. Their exclusion from diversity analyses does not reflect available data. The same is true for the previously assumed absence of teleosauroids in the phylogenetically uncorrected dataset, during the Aalenian and Bajocian. In both of these stages, no thalattosuchian remains are known, however they are clearly present before and after these stages. The presence of at least one species should, therefore, be considered in diversity analyses, even if its phylogenetic relationships are not considered (Appendices 1, 2). Thus, they are herein introduced as "unidentified thalattosuchians" for the Sinemurian-Pliensbachian forms and as "ghost lineage" for the Aalenian-Bajocian absent forms.

\section{Taxonomic Corrections}

Similarly the taxonomic status of the studied taxa can also have effects on the results of quantitative analyses at specific or generic levels. It is particularly true for the unreviewed teleosauroid thalattosuchians. Most of them are still awaiting deep review for the validity of numerous species. Nevertheless, part of them, the blunt-toothed Machimosaurini, have recently received a little more attention. In particular, recent debates focused on the number of Machimosaurus species. Based on examination of morphospace occupation, pair-wise significance tests and cluster analysis, Pierce et al. (2009) suggested at least two species for Machimosaurus: $M$. mosae and $M$. hugii. This interpretation was challenged by Martin and Vincent (2013) and Martin et al. (2015) who recognized only one species, $M$. hugii. Young et al. (2014) considered four species: $M$. nowakianus (upper Oxfordian or lower Kimmeridgian), M. burgensis $(=M$. buffetauti; lower Kimmeridgian; Martin et al., 2015), M. mosae (upper Kimmeridgian-lower Tithonian), and $M$. hugii (upper Kimmeridgianlower Tithonian). Like Foffa et al. (2015) and Fanti et al. (2016), we consider that the weakness of some diagnostic characters pointed out by Martin et al. (2015) do not affect the validity of the species described by Young et al. (2014). The reassessment of the content of Machimosaurus is largely beyond the scope of the present paper, for the above-mentioned reasons, we support the revision of Young et al. (2014) and consider four valid species, plus the recently described Machimosaurus 


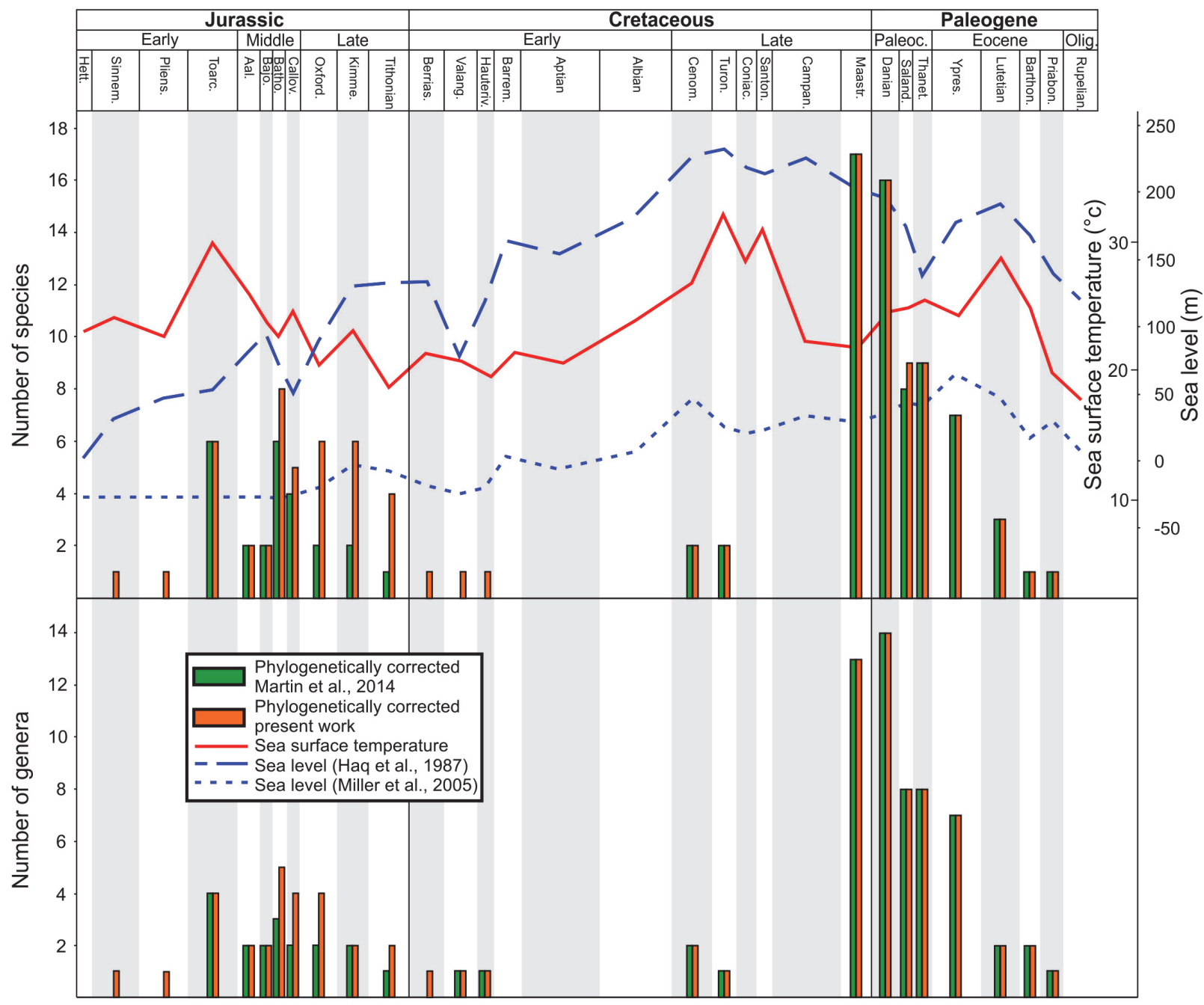

FIGURE 1. Comparison between the diversity count of Jurassic-Paleogene marine crocodylomorphs (excluding metriorhynchoids) of Martin et al. (2014) (excluding Pelagosaurus typus), with the data obtained in the present work after several corrections. All the data is phylogenetically corrected. The data used in the present work includes four new species, corrections for the number of Machimosaurus species, and taxonomical corrections (see text).

rex (Fanti et al., 2016). The impact of these taxonomic modifications was tested in the original analyses (Appendices 1, 2). These taxonomic modifications also have strong consequences for the phylogenetically corrected diversity (Figure 1).

\section{Generic or Specific Level}

Martin et al. (2014) considered that the use of genera in the dataset allows for the smoothing out of diversity counts across different lineages and reducing taxonomic biases. However, this should be discussed since a species is a natural entity, whereas supraspecific clades, including genera, are arbitrary sets. As such, the genus entity is arbitrary; it is not equivalent across different lineages, but brings another kind of bias, the choice of taxon- omists to group more or less large sets of species under the same supraspecific name. Lloyd et al. (2012) demonstrated with one of the best available fossil records (microfossils) that higher taxa cannot be taken as unbiased proxies for species diversity. For our concerned dataset, if most of the marine crocodylomorph taxonomy has been extensively reviewed, such as those of dyrosaurids (Jouve, 2004; Jouve et al., 2005, 2008b; Hastings et al., 2015) and crocodylians (e.g., Brochu, 1999, 2013; Jouve, 2016; Jouve et al., 2008a, 2014), the teleosauroids are far from being seriously reviewed. Only an unpublished thesis proposed a review of the thalattosuchians (Vignaud, 1995), but did not adopt a cladistic analysis of their phylogenetic studies. 


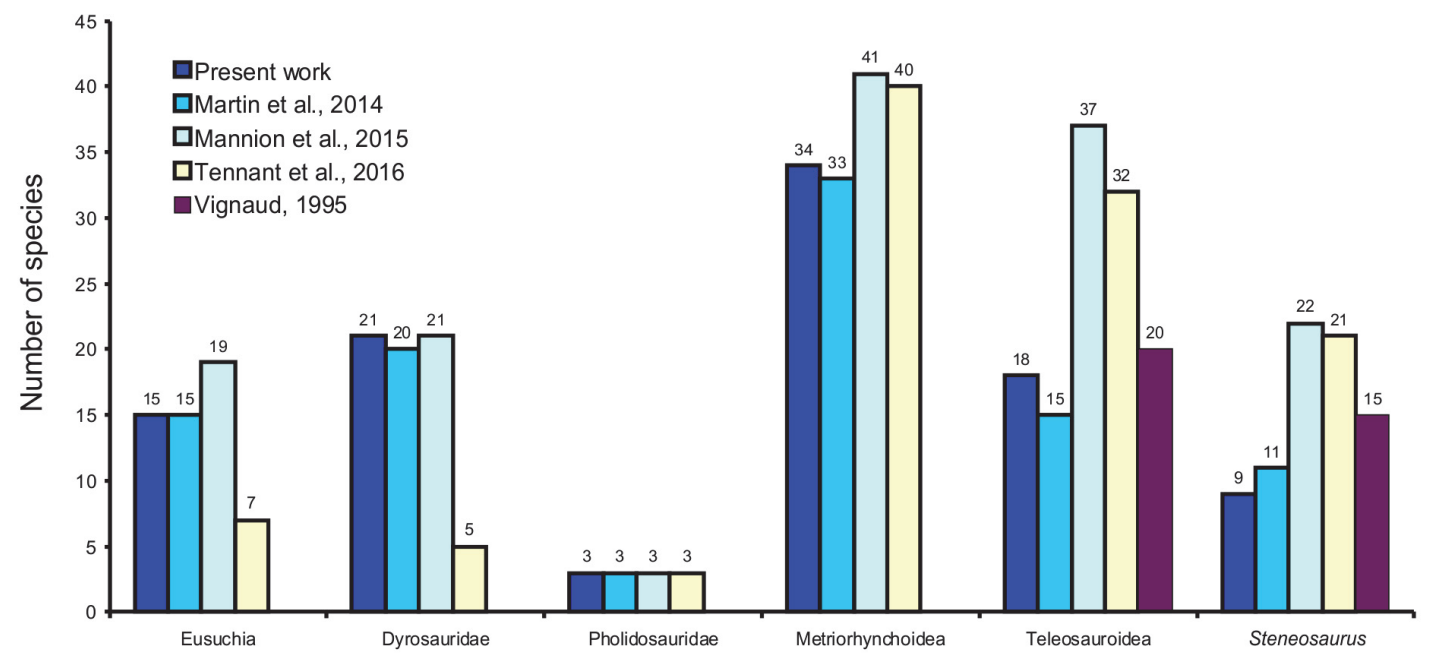

\section{Marine crocodylomorph diversity (species)}

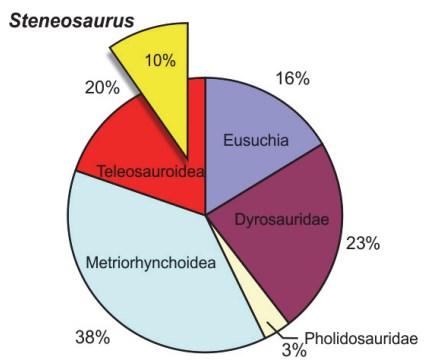

Present work

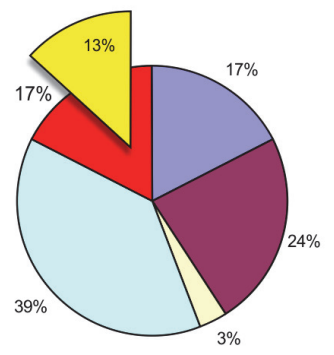

Martin et al., 2014

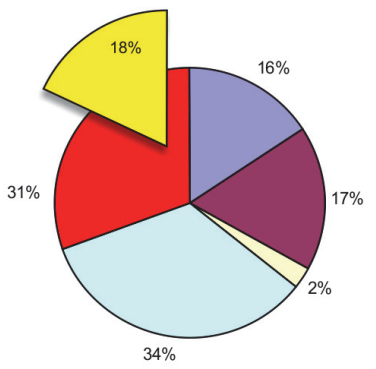

Mannion et al., 2015

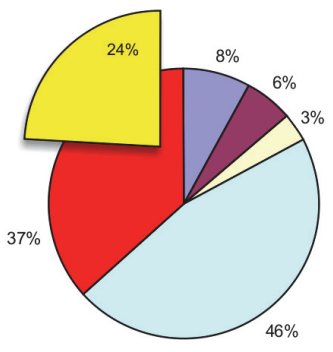

Tennant et al., 2016
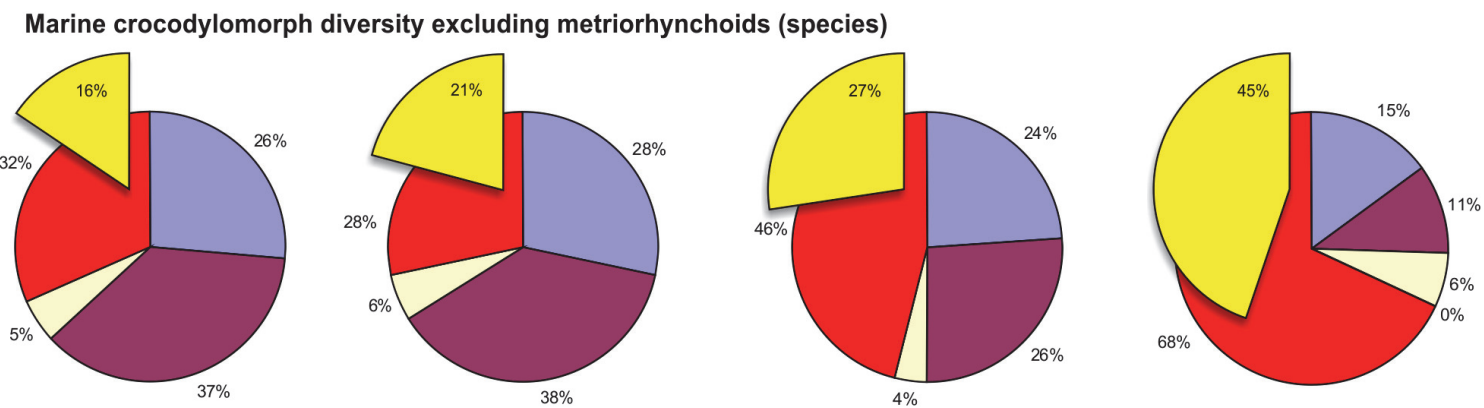

FIGURE 2. Comparison of the crocodylomorph species diversity used in various studies. 1, comparison of the number of species used for each marine crocodylomorph group; 2, comparison of the per cent of each group and of the genus Steneosaurus in the marine crocodylomorph diversity used (with and without metriorhynchoids).

Thus, the number of valid species included in the analyses strongly varies depending on the study. While Martin et al. (2014) considered 11 Steneosaurus species, representing nearly $21 \%$ of the number of marine species considered in the analysis (excluding metriorhynchoids), Tennant et al. (2016) and Mannion et al. (2015) included more than 20 species for this genus (Figure 2.1). In the present analyses and those of Martin et al. (2014), the Steneosaurus species represent 10 to $13 \%$ of the marine crocodylomorph diversity, and 16 to $21 \%$ when the metriorhynchoids are excluded (Figure 2.2). They form $18 \%$ of the marine crocodylomorph diversity in Mannion et al. (2015), 27\% when the metriorhynchoids are excluded, $24 \%$ in Tennant et al. (2016), and 45\% without the metriorhynchoids (Figure 2.2). The consequence of the absence of phylogenetic analysis of the teleosau- 
roids is that most of the teleosauroid species have been included in Steneosaurus, underestimating the teleosauroid diversity and the number of existing genera. This could have a strong impact on the analyses, as teleosauroid species represent nearly one-third of the species included in our dataset when the metriorhynchoids are excluded (Figure 2.2). Using the taxonomy provided by Martin et al. (2014), $73 \%$ of the teleosauroid species are part of the genus Steneosaurus (Appendices 1, 3, 4). However, the taxonomy of the metriorhynchoid thalattosuchians has been recently reviewed (Young et al., 2010) and the most diverse metriorhynchoid genus (Cricosaurus) represents only $22 \%$ of the known species. It could be proposed that the teleosauroids were in reality much more generically diverse than suggested and composed of more than just four genera. Recent phylogenetic analyses included several Steneosaurus species. Five to six species were included, and the result suggests that only two form a monophyletic clade (Young et al., 2012), and two are distributed in two different clades in Wilberg (2015a, 2015b).

The species number is also problematic. Tennant et al. (2016) and Mannion et al. (2015) included 32 and 37 teleosauroids respectively, representing 60 to $85 \%$ more than the number of species recognized in the only teleosauroid review (Vignaud, 1995; Figure 2; Appendix 3) and more than twice the number of species included in the Martin et al. (2014) analyses (15 species) (Figure 2.1; Appendix 4). As Tennant et al. (2016) included only Jurassic-Cretaceous forms, the proportion of the teleosauroids is particularly huge $(37 \%$ and even $68 \%$ when the metriorhynchoids are excluded). At the genus level, the differences between the four studies are lesser (Figure 3.1), the teleosauroids constitute 11 to $18 \%$ of the marine crocodylomorph diversity, and a larger percentage when metriorhynchoids are excluded (16 to $35 \%$ ) (Figure 3.2).

The sources of the dataset are thus problematic. Tennant et al. (2016) and Mannion et al. (2015) gathered their data from the Paleobiology Database, a useful database, but not necessarily up-to-date taxonomically. Several species of dyrosaurids such as Dyrosaurus choumovitchi, D. berneti, and $D$. variabilis are considered valid and were used in diversity analyses by Mannion et al. (2015), while they were synonymised by Jouve (2005) (see Appendix 3). Numerous taxonomic assignments are also particularly doubtful, such as a large number of taxa erected in the nineteenth century on the basis of poorly defined remains.
This is the case for a large number of Teleosaurus species considered in this database (7), when Vignaud (1995) recognised only two or even three different species. The same is true for the 22 Steneosaurus species recognised in Mannion et al. (2015) and 21 species in Tennant et al. (2016), when Vignaud (1995) only considered 15 valid species (Figure 2; Appendix 3). Several of these species have been rejected in recent publications such as S. gerthi (Gasparini and Fernandez, 2005) and S. dasycephalus (Woods, 2010). Other nineteenth-century species considered in diversity analyses are also based on isolated teeth such as Thoracosaurus bahiensis Marsh, 1869, and Haematosaurus lanceolatus Sauvage, 1874. This strongly questions the reliability of the results.

Studies based on genus level avoid the problem of the large number of Steneosaurus species and of the doubtful species, but underestimate the number of the teleosauroid genera. The results obtained with the analyses of generic and specific diversity, must be compared, particularly for the teleosauroid diversity analysis.

\section{Phylogenetic Corrections}

The analyses of raw data were performed and, following Martin et al. (2014), we also conducted correlation analyses of phylogenetically corrected data. The phylogenetic relationships are thus superimposed on the stratigraphy and ghost lineages of genera and species are filled (Appendices 1,2$)$ following the method proposed by Cavin and Forey (2007). Most of the marine crocodylomorphs have been reviewed, and several papers are available to drive phylogenetic corrections on the diversity datasets. Dyrosaurids are phylogenetically corrected following Hastings et al. (2015). Martin et al. (2014) did not correct the eusuchian diversity because of the controversial phylogenetic relationships between gavialoids and tomistomines. We did not correct the eusuchian diversity either. Indeed, if dyrosaurids and most of the thalattosuchians are recognised as almost strictly marine forms, it is not strictly the case for the eusuchians. Most eusuchians were/are fresh water animals. So, it cannot be ensured that the species represented by the ghost lineages were marine forms, and no phylogenetic corrections have been conducted for the eusuchian diversity.

Thalattosuchian diversity has also been phylogenetically corrected. As the teleosauroids are still awaiting a deep revision, no complete phylogeny exists for them and only some analyses include a subset of the teleosauroid (Young et al., 

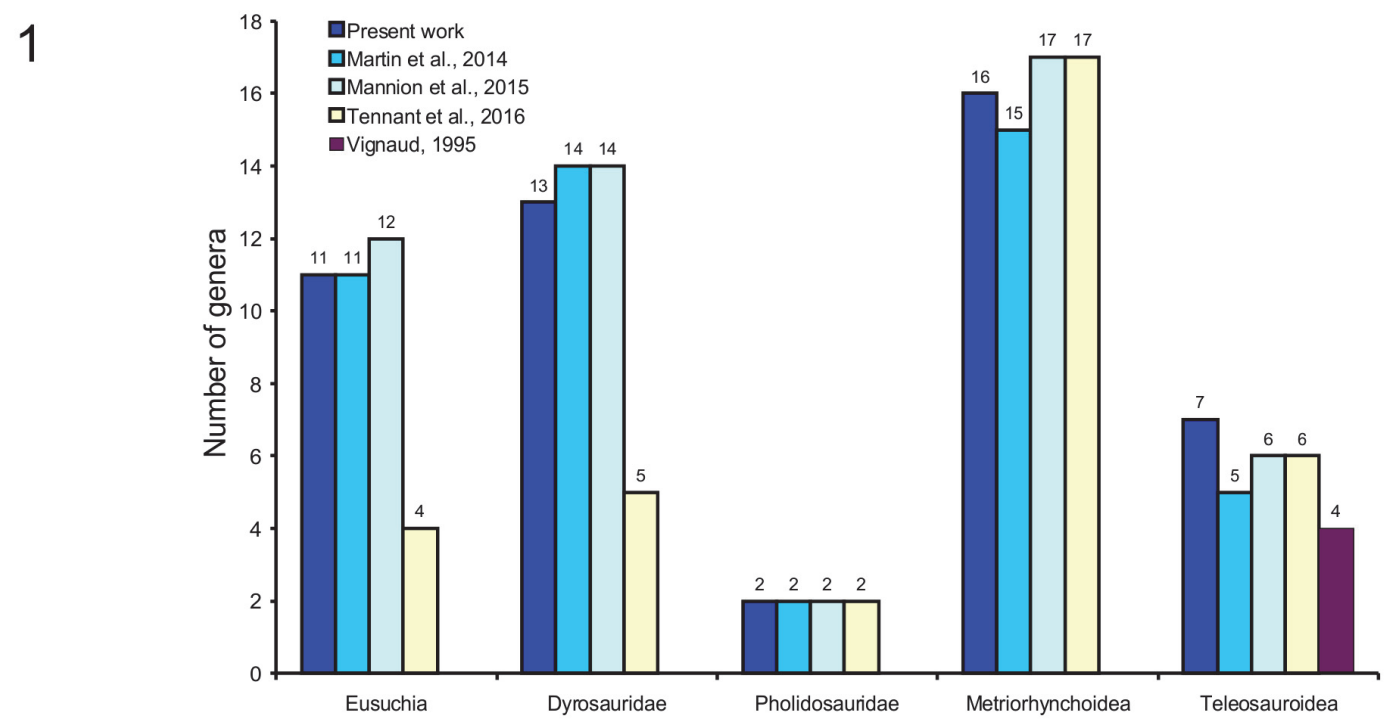

2

Marine crocodylomorph diversity (genera)

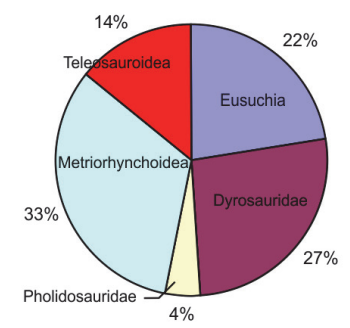

Present work

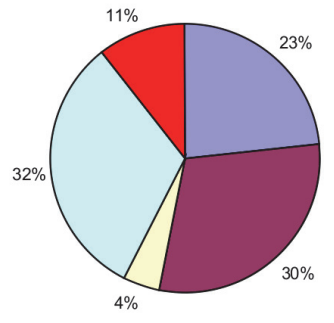

Martin et al., 2014

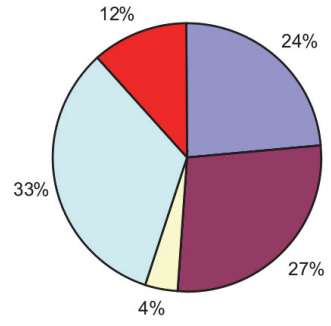

Mannion et al., 2015

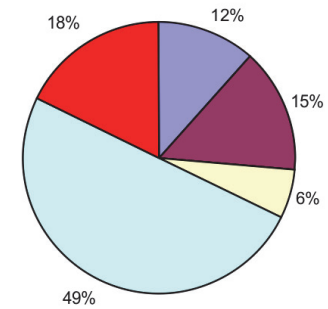

Tennant et al., 2016

Marine crocodylomorph diversity excluding metriorhynchoids (genera)
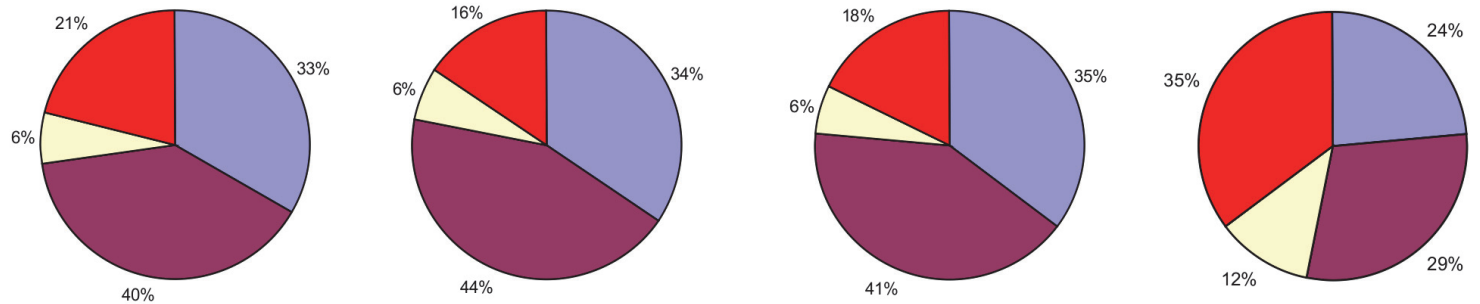

FIGURE 3. Comparison of the crocodylomorph genus diversity used in various studies. 1, comparison of the number of genera used for each marine crocodylomorph group; 2 , comparison of the percent of each group used in the marine crocodylomorph diversity (with and without metriorhynchoids).

2012; Wilberg, 2015a, 2015b). Mueller-Töwe $(2005,2006)$ proposed the first phylogenetic analysis of the teleosauroids. However, Jouve (2009) pointed out that, the outgroups used in this analysis were inadequate and could impact on the ingroup relationships, the result should then be considered with caution. Only three recent phylogenetic analyses introduce more than six teleosauroid species (Young et al., 2012; Wilberg, 2012, 2015a, 2015b; Fanti et al., 2016), but they do not consider the same species. Wilberg $(2012,2015 a)$ does not include Machimosaurus nor close spe- cies, such as "Steneosaurus" obtusidens, yet later he includes Machimosaurus hugii, but not "Steneosaurus" obtusidens (Wilberg, 2015b). Fanti et al. (2016), based on Young et al. (2012), is the first to include four Machimosaurus species and "Steneosaurus" obtusidens in a phylogenetic analysis. Their result is used as framework for our diversity analysis and phylogenetic corrections are compared to the original data (Martin et al., 2014). Following the same analyses, two taxa are also differently considered herein: "Steneosaurus" edwardsi and "Steneosaurus" obtusidens. The 
results suggest that these species are more closely related to the blunt-toothed teleosauroids than to the other Steneosaurus. We thus tested "Steneosaurus" edwardsi and "Steneosaurus" obtusidens as different genera in the taxonomical corrections (Appendices 1, 2). Pelagosaurus typus is attributed to the metriorhynchoid in all previously cited phylogenetic analyses and excluded from teleosauroids. Consequently, as we conducted analyses on the crocodylomorphs diversity excluding metriorhynchoids, this species is not part of our analyses.

Several datasets have been tested for species and genera in relation with various corrections (raw data, new material and species, unidentified taxa and ghost lineages, and including all these corrections). Each of these eight datasets has been phylogenetically corrected and tested (Appendices 1, 2).

\section{Time Intervals}

Martin et al. (2014) considered the analyses from Lower Jurassic (Hettangian) to Lower Oligocene (Rupelian). However, since there is no marine crocodylomorph in the time interval from the Hettangian to the Pliensbachian in their dataset, we have tested the correlations for two different time intervals: Pliensbachian-Rupelian and ToarcianPriabonian. The latter (Toarcian-Priabonian) brackets a time interval that contains marine crocodylomorphs, whereas the first (PliensbachianRupelian) includes a stage before (Pliensbachian) and a stage after (Rupelian) that do not contain marine crocodylomorph. We follow the same strategy for the study of the teleosauroid diversity, using Hettangian-Berriasian and Pliensbachian-Berriasian intervals. Thus, we tested the effect of the time interval used on the results.

\section{Sea Surface Temperature}

The sea surface temperature is established from $\delta^{18} \mathrm{O}$ values of fish teeth from the Western Tethys (Martin et al., 2014) and differs from the $\delta 180$ palaeotemperature proxies from the compendium provided by Prokoph et al. (2008) from marine carbonates. Mannion et al. (2015) suggested one possible problem with $\delta^{180} \mathrm{~V}$ values of fish teeth (possible specific differences in isotopic fractionation between phosphate and water), but Leuzinger et al. (2015) demonstrated constant and coherent values between chondrichthyan fauna, with an unusual values for a unique species probably due to a freshwater-influenced isotopic composition. So, no evidence seems to justify this doubt on the methodology used on fish teeth. While the direct use of $\delta^{18} \mathrm{O}$ from marine carbonates provide a proxy for general temperature and climatic evolution, the sea surface temperature (SST) is a proxy of the evolution of Tethyan sea temperatures (all values originated from Tethyan fishes), and could provide different information from $\delta^{18} \mathrm{O}$.

Most of the problems with these data is bias due to inconsistent sampling across the time span that could impact the means (Kelley et al., 2014), particularly the Palaeocene-Eocene time interval (Figure 4). Only one value is available for the Lutetian-Priabonian interval (nearly $14 \mathrm{My}$ ) and 11 are available for the Palaeocene-Eocene (32 My), while the temperature intervals are particularly wide for the periods with numerous data (span of $16^{\circ} \mathrm{C}$ for the Bathonian). The use of means could, therefore, be inconsistent and problematic. To avoid this problem and limit its impact on the curve used in the analyses, a polynomial curve has been constructed in OpenOffice 4 with the add-on CorelPolyGUI (Gutman et al., 2012) and theoretical values from this polynomial curve are obtained for each interval mid-point with the same add-on (Appendix 5). We also constructed a curve with smoothing spline using Past 3.10 (Hammer et al., 2001), with the optimised smoothing (9.625), and two curves with three-point moving average and with weighted three-point moving average approaches (Appendix 6). In the weighted and non-weighted three-point moving average each value is the mean of the original mean and its two neighbours. The weight is of 0.5 for the neighbours in the weighted three-point moving average.

\section{Statistical Analyses}

We calculated the correlation between the sea surface temperature (Martin et al., 2014), the sea level from Haq et al. (1987) and Miller et al. (2005), and the marine crocodylomorph diversity excluding metriorhynchoids (Appendix 7). The first diversity count used is that from Martin et al. (2014) only excluding Pelagosaurus typus compared with the same dataset including new material and species (new Moroccan blunt-toothed teleosauroid [Jouve et al., 2016]; Oxfordian "Steneosaurus" cf obtusidens [Foffa et al., 2015], Machimosaurus rex; Anthracosuchus balrogus [Hastings et al., 2015]). Both datasets have been tested for three time intervals: Hettangian-Rupelian, PliensbachianRupelian, and Toarcian-Priabonian. "Unidentified teleosauroids" and "ghost lineage" have also been added to this dataset and compared with the correlations obtained when new material and species and taxonomic corrections are included (number of 


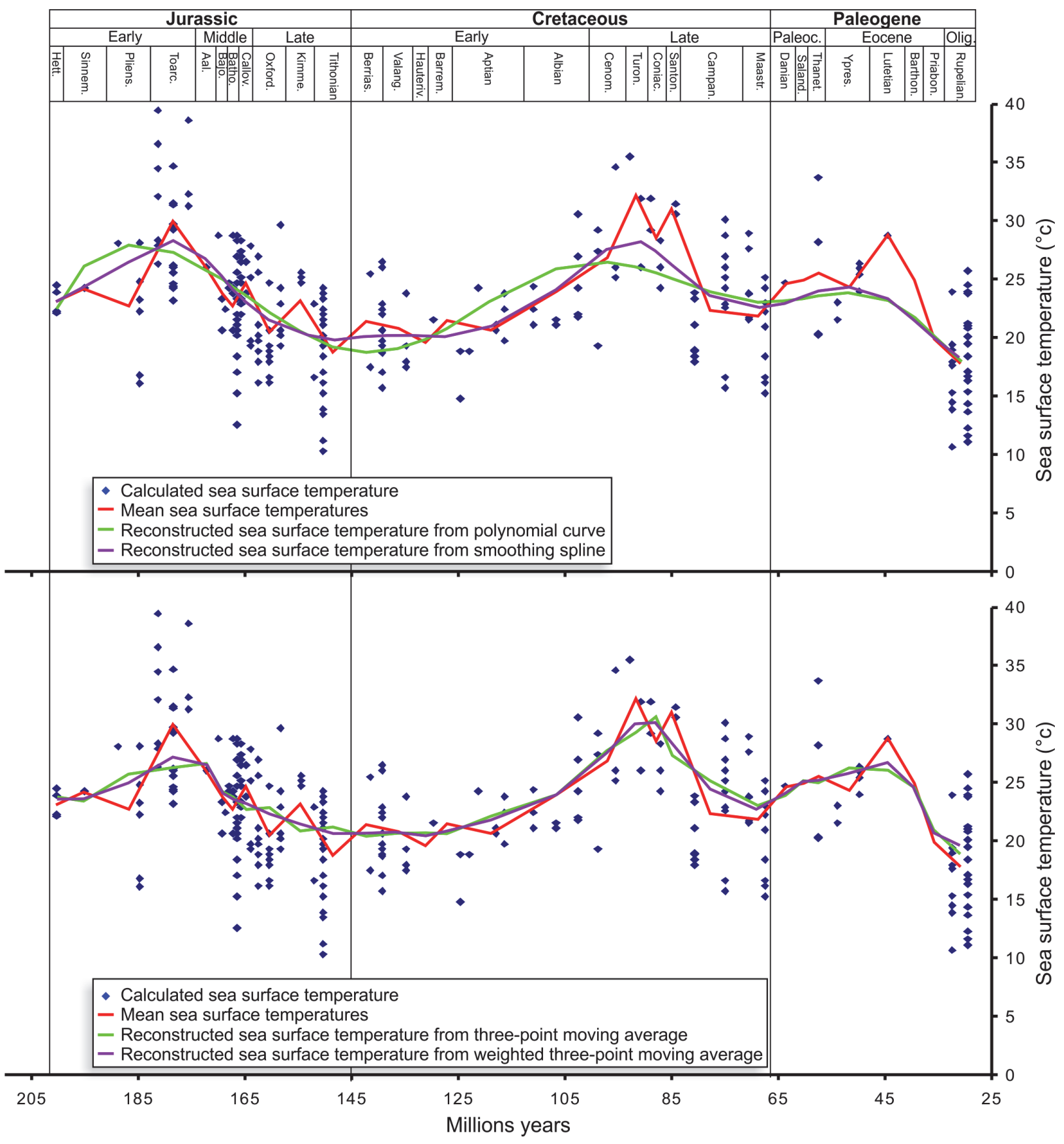

FIGURE 4. Evolution of the sea surface temperature. Comparison of the raw data (Martin et al., 2014) with the curve obtained with the mean for each time interval and the curve obtained with the theoretical data calculated from the polynomial curve, smoothing spline, and two curves with three-point moving average and with weighted three-point moving average approaches.

Machimosaurus species; "Steneosaurus" edwardsi as a different genus) (Appendix 8). The same comparisons have been conducted for the study of the correlation of the teleosauroid diversity, to environmental factors (sea level and temperature), but the time intervals studied are different and shorter: Hettangian-Berriasian, Pliensbachian-Berriasian,
Hettangian-Barremian, and Pliensbachian-Barremian (Appendix 9). For each dataset the results have been studied for the phylogenetically corrected data, log-transformed, time-corrected (divided by duration of time bin), and generalizeddifferenced data (Appendix 6), similarly to Martin et al. (2014). Finally, all data have been tested with 
TABLE 1. Number of significant correlations between sea surface temperature, sea level, and marine crocodylomorph diversity (excluding metriorhynchoids), according to the corrections conducted on the datasets and time interval considered. All curves are reconstructed from means for each geological stage. Spearman rank correlation with Spearman's rho values. Abbreviations: SST, sea surface temperature (Martin et al., 2014); SL-H, sea level (Haq et al., 1987); SL-M, sea level (Miller et al., 2005); Hett-Rup, Hettangian-Rupelian; Pli-Rup, Pliensbachian-Rupelian; To-Pria, Toarcian-Priabonian.

\begin{tabular}{|c|c|c|c|c|c|c|c|c|c|c|}
\hline & & \multicolumn{9}{|c|}{$\begin{array}{c}\text { Marine crocodylomorph diversity } \\
\text { (metriorhynchoids excluded) } \\
\text { Mean curve }\end{array}$} \\
\hline & & $\begin{array}{c}\text { SST } \\
\text { Hett-Rup }\end{array}$ & $\begin{array}{c}\text { SL-H } \\
\text { Het-Rup }\end{array}$ & $\begin{array}{c}\text { SL-M } \\
\text { Het-Rup }\end{array}$ & $\begin{array}{c}\text { SST } \\
\text { Pli-Rup }\end{array}$ & $\begin{array}{c}\text { SL-H } \\
\text { Pli-Rup }\end{array}$ & $\begin{array}{l}\text { SL-M } \\
\text { Pli-Rup }\end{array}$ & $\begin{array}{c}\text { SST } \\
\text { To-Pria }\end{array}$ & $\begin{array}{l}\text { SL-H } \\
\text { To-Pria }\end{array}$ & $\begin{array}{c}\text { SL-M } \\
\text { To-Pria }\end{array}$ \\
\hline \multirow[t]{3}{*}{ Original data } & $\begin{array}{l}\text { Genus, } \\
p<0.05\end{array}$ & 4 & 0 & 3 & 0 & 0 & 3 & 0 & 0 & 3 \\
\hline & $\begin{array}{l}\text { Species, } \\
p<0.05\end{array}$ & 6 & 0 & 3 & 5 & 0 & 3 & 0 & 0 & 2 \\
\hline & $\begin{array}{l}\text { Total, } \\
p<0.05\end{array}$ & 10 & 0 & 6 & 5 & 0 & 6 & 0 & 0 & 5 \\
\hline \multirow[t]{3}{*}{$\begin{array}{l}\text { Original data }+ \text { new } \\
\text { material and species }\end{array}$} & $\begin{array}{l}\text { Genus, } \\
p<0.05\end{array}$ & 1 & 0 & 3 & 0 & 0 & 3 & 0 & 0 & 2 \\
\hline & $\begin{array}{l}\text { Species, } \\
p<0.05\end{array}$ & 2 & 0 & 3 & 2 & 0 & 2 & 0 & 0 & 0 \\
\hline & $\begin{array}{l}\text { Total, } \\
p<0.05\end{array}$ & 3 & 0 & 6 & 2 & 0 & 5 & 0 & 0 & 2 \\
\hline \multirow{3}{*}{$\begin{array}{l}\text { Original data } \\
\text { +unidentified } \\
\text { thalattosuchians } \\
\text { +ghost lineages }\end{array}$} & $\begin{array}{l}\text { Genera, } \\
p<0.05\end{array}$ & 5 & 0 & 1 & & & & & & \\
\hline & $\begin{array}{l}\text { Species, } \\
p<0.05\end{array}$ & 3 & 0 & 1 & & & & & & \\
\hline & $\begin{array}{l}\text { Total, } \\
p<0.05\end{array}$ & 8 & 0 & 2 & & & & & & \\
\hline \multirow[t]{3}{*}{ All corrections } & $\begin{array}{l}\text { Genera, } \\
p<0.05\end{array}$ & 0 & 0 & 1 & & & & & & \\
\hline & $\begin{array}{l}\text { Species, } \\
p<0.05\end{array}$ & 0 & 0 & 0 & & & & & & \\
\hline & $\begin{array}{l}\text { Total, } \\
p<0.05\end{array}$ & 0 & 0 & 1 & & & & & & \\
\hline
\end{tabular}

the sea surface temperature calculated with the polynomial curve (Appendices 10-12), the threepoint moving average (Appendices 13-15), smoothing spline (Appendices 16-18), and weighted three-point moving average (Appendices 19-21).

Spearman's rho values and 1184 Spearman rank correlations have been calculated (Appendices 7-21) using Past 3.10 (Hammer et al., 2001). Generalized differencing of time series were calculated with R 3.2.1 (R Core Team 2015) and a script provided by Graeme Lloyd (2008).

\section{RESULTS AND DISCUSSION}

\section{Marine Crocodylomorph Diversity Dynamics}

Similarly to Martin et al. (2014), a correlation is found between the evolution of the crocodylo- morph diversity and sea surface temperature when Pelagosaurus is considered as a metriorhynchoid and excluded from the diversity analyses (Spearman's $r=0.36019$; $p=0.045243$; Appendix 7). On the contrary, no correlation is found when some new material and species published after the Martin et al. (2014) paper are included in the analysis (Spearman's $r=0.27493$; $p=0.13442$; Appendix 7). The new specimens and species change the raw diversity count in adding four new occurrences. This seems to impact the correlation analyses provided by Martin et al. (2014) between sea surface temperature and marine crocodylomorphs (excluding metriorhynchoids) with raw data. When we tested some of the data treatments provided by Martin et al. (2014) (phylogenetically corrected data, logarithm, time-corrected, and generalizeddifferenced data), with only one modification 
(exclusion of the Pelagosaurus), we found 10 statistically significant correlations with the sea surface temperature (seven in Martin et al., 2014), but only three when the new material and species were introduced (Table 1; Appendix 7). In both cases, whether with or without the new material, six significant correlations are found with the sea level provided by Miller et al. (2005) (five in Martin et al., 2014; Table 1; Appendix 7). With these results, we cannot confirm that marine crocodylomorph evolution is more related to the sea surface temperature than to the sea level. On the contrary, the number of significant correlations with the Miller et al. (2005) sea level data is twice the number of correlations with the sea surface temperature. Introducing four new occurrences (the Moroccan Machimosaurin, "S." cf. obtusidens, Machimosaurus rex, Anthracosuchus balrogus) strongly changes the diversity counts and the phylogenetic corrections of the diversity (Figure 1), particularly for the thalattosuchians, and strongly impacts the results of the analyses (Table 1).

Testing the Pliensbachian-Rupelian time interval, the difference in correlations is particularly marked when the new material and species are introduced. For this time interval and for the Toarcian-Priabonian, the number of correlations is higher with the sea level data provided by Miller et al. (2005) than with the sea surface temperature (Table 1; Appendix 7). The results strongly vary according to the time bins considered, as well as with the insertion of only four new crocodylomorph occurrences.

Poorly preserved fossils of teleosauroids are known in the Sinemurian and Pliensbachian stratigraphic levels and were not included in the analysis by Martin et al. (2014). When these Lower Jurassic unidentified thalattosuchians and ghost lineage are included in the analyses, eight correlations are found with the sea surface temperature and two with the sea level data from Miller et al. (2005) (Table 1; Appendix 8). When new material and species, ghost lineages, and new taxonomical corrections are introduced in the dataset, only one correlation is found with the sea level of Miller et al. (2005) and none with the sea surface temperature (Table 1). The differences in the latter result is particularly of interest, as we have previously found three correlations with the sea surface temperature and six with sea level when only the new material and species were included. As the phylogenetic analyses can vary according to authors, it could be interesting to use and analyse the diversity raw data (uncorrected diversity), but the "unidentified thalattosuchians" and ghost lineage must be included when the presence of these taxa is certified, even if this presence is attested by poor material and not more precisely identified than the family level. When they are not, the diversity analysed is not the diversity observed. This also underlines the importance of a clear taxonomy and its impact on diversity estimation and analyses.

No correlation is found between the original data and polynomial (Appendix 10), three point moving average (Appendix 13), and smoothing spline curves (Appendix 16) for the sea surface temperature (Table 2). Two correlations were found with the weighted three-points moving average curve (Table 2; Appendix 19). This strongly contrasts with the 10 correlations found with the curve obtained with the sea surface temperature means (Tables 1,2). Only one significant correlation has been found with the curve obtained by three-point moving average when unidentified thalattosuchians and ghost lineage were introduced (Appendix 14), and two with the weighted three-point moving average (Table 2; Appendix 20). One correlation only was found (with smoothing spline curve) when unidentified thalattosuchians and ghost lineages were included (Table 2; Appendix 17). No correlation was found with any of the reconstruction methods used when all corrections were added (Table 2 ). These results strongly question the reliability of the sea surface temperature proxy (means) usually used for comparison with diversity curves. The means for this proxy are particularly biased, and they are not the best way to obtain the best proxy for the sea surface temperature dynamic thought geological times.

\section{Teleosauroid Diversity Dynamics}

The number of significant correlations varies according to the modifications in the dataset when the teleosauroid diversity is compared with the sea surface temperature and the sea level. With the original data (P. typus excluded), two correlations were found with the sea surface temperature, whereas none were found with the sea level, both when unidentified thalattosuchians and ghost lineage are included (Table 3; Appendix 9). Similar results are found when the new material and species are included, but no correlations are found with the sea level or the sea surface temperature when all the corrections are included: unidentified thalattosuchians, ghost lineages, taxonomical corrections, and new material and species (Table 3; Appendix 9). 
TABLE 2. Number of significant correlations between sea surface temperature and marine crocodylomorph diversity (excluding metriorhynchoids), according to the corrections conducted on the datasets and the method used to reconstruct the curve. Spearman rank correlation with Spearman's rho values.

\begin{tabular}{|c|c|c|c|c|c|c|}
\hline & & \multicolumn{5}{|c|}{$\begin{array}{l}\text { Marine crocodylomorph diversity } \\
\text { (metriorhynchoids excluded) } \\
\text { Sea surface temperature (Hettangian-Rupelian) }\end{array}$} \\
\hline & & Mean curve & \multirow{2}{*}{$\begin{array}{c}\begin{array}{c}\text { Polynomial } \\
\text { curve }\end{array} \\
0\end{array}$} & \multirow{2}{*}{$\begin{array}{c}\text { Three-point } \\
\text { moving } \\
\text { average }\end{array}$} & \multirow{2}{*}{$\begin{array}{c}\begin{array}{c}\text { Smoothing } \\
\text { spline curve }\end{array} \\
0\end{array}$} & $\begin{array}{l}\text { Weighted } \\
\text { three-point } \\
\text { moving } \\
\text { average }\end{array}$ \\
\hline Original data & $\begin{array}{l}\text { Genus, } \\
p<0.05\end{array}$ & 4 & & & & 1 \\
\hline & $\begin{array}{l}\text { Species, } \\
p<0.05\end{array}$ & 6 & 0 & 0 & 0 & 1 \\
\hline & $\begin{array}{l}\text { Total, } \\
p<0.05\end{array}$ & 10 & 0 & 0 & 0 & 2 \\
\hline \multirow[t]{3}{*}{ Original data +new material and species } & $\begin{array}{l}\text { Genus, } \\
p<0.05\end{array}$ & 1 & 0 & 0 & 0 & 0 \\
\hline & $\begin{array}{l}\text { Species, } \\
p<0.05\end{array}$ & 2 & 0 & 0 & 0 & 1 \\
\hline & $\begin{array}{l}\text { Total, } \\
p<0.05\end{array}$ & 3 & 0 & 0 & 0 & 1 \\
\hline \multirow[t]{3}{*}{$\begin{array}{l}\text { Original data +unidentified } \\
\text { thalattosuchians }+ \text { ghost lineages }\end{array}$} & $\begin{array}{l}\text { Genera, } \\
p<0.05\end{array}$ & 5 & 0 & 1 & 0 & 2 \\
\hline & $\begin{array}{l}\text { Species, } \\
p<0.05\end{array}$ & 3 & 0 & 0 & 0 & 0 \\
\hline & $\begin{array}{l}\text { Total, } \\
p<0.05\end{array}$ & 8 & 0 & 1 & 0 & 2 \\
\hline \multirow[t]{3}{*}{ All corrections } & $\begin{array}{l}\text { Genera, } \\
p<0.05\end{array}$ & 0 & 0 & 0 & 0 & 0 \\
\hline & $\begin{array}{l}\text { Species, } \\
p<0.05\end{array}$ & 0 & 0 & 0 & 0 & 0 \\
\hline & $\begin{array}{l}\text { Total, } \\
p<0.05\end{array}$ & 0 & 0 & 0 & 0 & 0 \\
\hline
\end{tabular}

The use of shorter time intervals consistently changes the results, particularly when the new species and material are introduced alone. However, no correlations are found when all corrections are introduced (Table 3; Appendix 9). The same is true for the differences between the results obtained with the genera and species.

A bias must be noted, pertaining to the absence of data for the sea level from the Hettangian-Aalenian in Miller et al. (2005), which represents one-third of the values used for the Hettangian-Barremian time interval. Consequently, the result obtained for the sea level cannot be considered with any confidence and correlation with this parameter cannot be excluded, nor really be tested.

We finally tested the correlation of the teleosauroid diversity with the evolution of the sea surface temperature obtained from the polynomial curve (Appendix 12), smoothing spline (Appendix 18 ), the three-point moving average (Appendix 15), and weighted three-point moving average (Figure 4; Appendix 21). One significant correlation has been found with the curve obtained with the polynomial curve when the unidentified thalattosuchians and ghost lineage were introduced and two with the weighted three-point moving average with the original data, when the new material and species are added and when unidentified thalattosuchians and ghost lineage were introduced. No correlations were found when all corrections were included (Table 3).

These results, as those discussed above, highlight the impact of the taxonomical modifications in the dataset on the correlation analyses. They also underline the differences in the results obtained with a dataset and its subset. When the marine crocodylomorphs are strongly correlated 
TABLE 3. Number of significant correlations between sea surface temperature, sea level, and teleosauroid diversity, according to the corrections conducted on the datasets, and the method used to reconstruct the curve. Spearman rank correlation with Spearman's rho values.

\begin{tabular}{|c|c|c|c|c|c|c|c|c|}
\hline & & \multicolumn{7}{|c|}{ Teleosauroid diversity } \\
\hline & & $\begin{array}{l}\text { Sea surface } \\
\text { temperature }\end{array}$ & $\begin{array}{c}\text { Sea level } \\
\text { Haq et al., } \\
1987\end{array}$ & $\begin{array}{l}\text { Sea level } \\
\text { Miller et } \\
\text { al., } 2005\end{array}$ & \multicolumn{4}{|c|}{ Sea surface temperature } \\
\hline & & & Mean curve & & $\begin{array}{l}\text { Polynomial } \\
\text { curve }\end{array}$ & $\begin{array}{c}\text { Three- } \\
\text { point } \\
\text { moving } \\
\text { average }\end{array}$ & $\begin{array}{l}\text { Smoothing } \\
\text { spline } \\
\text { curve }\end{array}$ & $\begin{array}{c}\text { Weighted } \\
\text { three-point } \\
\text { moving } \\
\text { average }\end{array}$ \\
\hline \multirow[t]{3}{*}{ Original data } & $\begin{array}{l}\text { Genus, } \\
p<0.05\end{array}$ & 1 & 0 & 0 & 0 & 0 & 1 & 1 \\
\hline & $\begin{array}{l}\text { Species, } \\
p<0.05\end{array}$ & 1 & 0 & 0 & 0 & 0 & 1 & 1 \\
\hline & $\begin{array}{l}\text { Total, } \\
p<0.05\end{array}$ & 2 & 0 & 0 & 0 & 0 & 2 & 2 \\
\hline \multirow{3}{*}{$\begin{array}{l}\text { Original data } \\
+ \text { new material } \\
\text { and species }\end{array}$} & $\begin{array}{l}\text { Genus, } \\
p<0.05\end{array}$ & 0 & 0 & 0 & 0 & 0 & 1 & 1 \\
\hline & $\begin{array}{l}\text { Species, } \\
p<0.05\end{array}$ & 2 & 0 & 0 & 0 & 0 & 0 & 1 \\
\hline & $\begin{array}{l}\text { Total, } \\
p<0.05\end{array}$ & 2 & 0 & 0 & 0 & 0 & 1 & 2 \\
\hline \multirow{3}{*}{$\begin{array}{l}\text { Original data } \\
\text { +unidentified } \\
\text { thalattosuchian } \\
\mathrm{s}+\text { ghost } \\
\text { lineages }\end{array}$} & $\begin{array}{l}\text { Genera, } \\
p<0.05\end{array}$ & 1 & 0 & 0 & 1 & 0 & 2 & 1 \\
\hline & $\begin{array}{c}\text { Species, } \\
p<0.05\end{array}$ & 1 & 0 & 0 & 0 & 0 & 1 & 1 \\
\hline & $\begin{array}{c}\text { Total, } \\
p<0.05\end{array}$ & 2 & 0 & 0 & 1 & 0 & 3 & 2 \\
\hline \multirow[t]{3}{*}{ All corrections } & $\begin{array}{l}\text { Genera, } \\
p<0.05\end{array}$ & 0 & 0 & 0 & 0 & 0 & 1 & 0 \\
\hline & $\begin{array}{c}\text { Species, } \\
p<0.05\end{array}$ & 0 & 0 & 0 & 0 & 0 & 0 & 0 \\
\hline & $\begin{array}{c}\text { Total, } \\
p<0.05\end{array}$ & 0 & 0 & 0 & 0 & 0 & 1 & 0 \\
\hline
\end{tabular}

with sea surface temperatures with the original data (10 correlations), the subset, the teleosauroids, are poorly correlated (two correlations; Table 3). The same is true for the corrected data, when the marine crocodylomorphs are correlated with sea surface temperature or sea level, the correlations of teleosauroids with these proxies are weak.

\section{CONCLUSIONS}

Several new crocodylomorph species are described each year. For this reason we tested the impact of the introduction of some new species on a dataset that is only two years old. These insertions in the diversity analyses consistently change the results of the correlation analyses. Moreover, we demonstrate the existence of genus and species of the studied group in time intervals for which previous analyses considered the absence of any taxon. Does the use of raw data make any sense, as the use of unidentified taxa or ghost lineages observed without the use of any phylogenetic correction (using only taxonomy) demonstrated that this data is biased? The inclusion of these specimens in the analyses consistently changes the results herein and should be considered in future works.

The taxonomic and phylogenetic background is also of particular importance when studying the environmental causes for the evolution of a group. If taxonomical debates can sometimes seem pointless, the disagreement on the number of Machimosaurus species changes the teleosauroid diversity for the Late Jurassic from one to four species. In the same way, as the teleosauroids have never been reviewed, the number of valid Steneosaurus 
species considered in the analyses considerably varies from nine to 22, and the number of the whole teleosauroids from 15 to 37 (Figure 2.1), questioning the reliability of the results.

Little attention has been paid on the possible biases related to the time interval used in diversity analyses. Should the time interval used consider the stages during which the studied group is present, or also add a stage before and after the time interval with occurrences? This point should be more deeply investigated, but it is shown here that this parameter also strongly impacts the results and conclusions.

Quality of the data used to reconstruct the proxy curves should also be considered with attention. The data used to reconstruct the sea surface temperature are particularly inconsistent due to sampling biases. We explored herein several reconstruction methods and demonstrated that the results completely differ from those obtained with the method (means) used in previous publications. So, we consider that the sea surface temperature data cannot be used with enough confidence until the publication of more values, particularly for several geological stages with rare data. Alternatively, future correlation analyses should compare the results obtained with various reconstruction methods to evaluate their reliability.

We also compared the results obtained with the complete dataset and a subset. Why do the results of the subset strongly differ from those obtained with whole datasets? Does this result demonstrate a difference of the subset tested to the environmental fluctuations tested or the influence of the biases observed and described herein in this subset? These strong differences in the conclusions question the reliability of results in their entirety.

To conclude, the result proposed in Martin et al. (2014) should no longer be considered as reliable. The studies provided by Mannion et al. (2015) and Tennant et al. (2016) probably suffer from the same biases, such as the unreviewed taxonomy, that it is increased by the use of unreviewed data from the Paleobiology Database. Nevertheless, it is possible that the more complex statistical method used in both papers corrects some biases discussed here. The same empirical tests than those conducted in the present paper should be conducted on both datasets. The results provided herein should also be considered for the analyses of other clades. We thus suggest that deep taxonomic and phylogenetic review should be conducted prior to statistical analyses of diversity dynamics, as has been done recently on fishshaped marine reptiles (e.g., Fischer et al., 2012, $2014,2016)$, to maximally reduce potential biases.

\section{ACKNOWLEDGEMENTS}

BM and JD thank K. Schaffer, L. Leuzinger, N. Bardet, P. Vincent, and S. Daillie for fruitful discussions. We are grateful to D. Hembree and two anonymous reviewers for their comments. They contributed largely to strongly improve the quality of the present work. We also thank J. Jones and T. Fairbanks Freund for the English grammar review.

\section{REFERENCES}

Alroy, J. 2010a. Geographical, environmental and intrinsic biotic controls on Phanerozoic marine diversification. Palaeontology, 53:1211-1235.

Alroy, J. 2010b. The shifting balance of diversity among major marine animal groups. Science, 329:11911194.

Bardet, N., Falconnet, J., Fischer, V., Houssaye, A., Jouve, S., Pereda Suberbiola, X., Pérez-García, A., Rage, J.-C., and Vincent, P. 2014. Mesozoic marine reptile palaeobiogeography in response to drifting plates. Gondwana Research, 26:869-887.

Benson, R.B.J., Mannion, P.D., Butler, R.J., Upchurch, P., Goswami, A., and Evans, S.E. 2013. Cretaceous tetrapod fossil record sampling and faunal turnover: Implications for biogeography and the rise of modern clades. Palaeogeography, Palaeoclimatology, Palaeoecology, 372: 88-107. doi:10.1016/j.palaeo.2012.10.028

Benson, R.B.J. and Druckenmiller, P.S. 2014. Faunal turnover of marine tetrapods during the Jurassic-Cretaceous transition. Biological Reviews, 89:1-23.

Benton, M.J., Ruta, M., Dunhill, A.M., and Sakamoto, M. 2013. The first half of tetrapod evolution, sampling proxies, and fossil record quality. Palaeogeography, Palaeoclimatology, Palaeoecology, 372:18-41.

Brochu, C.A. 1999. Phylogenetics, taxonomy, and historical biogeography of Alligatoroidea. Journal of Vertebrate Paleontology, memoir 6:9-100.

Brochu, C.A. 2013. Phylogenetic relationships of Palaeogene ziphodont eusuchians and the status of Pristichampsus Gervais, 1853. Earth and Environmental Science Transactions of the Royal Society of Edinburgh, 103:521-550.

Cavin, L. and Forey, P.L. 2007. Using ghost lineages to identify diversification events in the fossil record. Biology Letters, 3:201-204.

Fanti, F., Miyashita, T., Cantelli, L., Mnasri, F., Dridi J., Contessi , M., and Cau, A. 2016. The largest thalattosuchian (Crocodylomorpha) supports teleosaurid survival across the Jurassic-Cretaceous boundary. Cretaceous Research, 61:263-274.

Fischer, V., Bardet, N., Benson, R.B.J., Arkhangelsky, M. S., and Friedman, M. 2016. Extinction of fish-shaped 
marine reptiles associated with reduced evolutionary rates and global environmental volatility. Nature Communications, 7:10825.

doi: 10.1038/ncomms10825

Fischer, V., Bardet, N., Guiomar, M., and Godefroit, P. 2014. High diversity in Cretaceous Ichthyosaurs from Europe prior to their extinction. PLOS ONE, 9:e84709.

doi: 10.1371/journal.pone.0084709

Fischer, V., Maisch, M.W., Naish, D., Kosma, R., Liston, J., Joger, U., Krüger, F.J., Pérez, J.P., Tainsh, J., and Appleby, R.M. 2012. New ophthalmosaurid ichthyosaurs from the European Lower Cretaceous demonstrate extensive ichthyosaur survival across the Jurassic-Cretaceous boundary. PLOS ONE, 7:e29234.

doi:10.1371/journal.pone.0029234Foffa, D., Young, M.T., and Brusatte, S.L. 2015. Evidence of macrophagous teleosaurid crocodylomorphs in the Corallian Group (Oxfordian, Late Jurassic) of the UK. PeerJ, 3:e1497.

Gasparini, Z. and Fernandez, M. 2005. Jurassic marine reptiles of Neuquén Basin: records, faunas and their palaeobiogeographic significance, p. 279-294. In Veiga, G.D., Spalletti, L.A., Howell, J.A., and Schwarz, E. (eds.), The Neuquén Basin: a case study in sequence stratigraphy and basin dynamics. Geological Society, London, Special publications, 252.

Gutman, M., Balland-Poirier, L., Godard, L., and Vennberg, B. 2012. CorelPolyGUI 1.4.5. http://extensions.services.openoffice.org/fr/project/corelpolygui.

Hammer, Ø., Harper, D.A.T., and Ryan, P.D. 2001. PAST: Paleontological Statistics software package for education and data analysis. Palaeontologia Electronica, 4:9.

Haq, B.U., Hardenbol, J., and Vail, P.R. 1987. Chronology of fluctuating sea levels since the Triassic. Science, 235:1156-1167.

Hastings, A.K., Bloch, J.I., and Jaramillo, C.A. 2015. A new blunt-snouted dyrosaurid, Anthracosuchus balrogus gen. et sp. nov. (Crocodylomorpha, Mesoeucrocodylia), from the Palaeocene of Colombia. Historical Biology, 27:998-1022.

Jouve, S. 2004. Etude Des Crocodyliformes Fini Crétacé-Paléogène Du Bassin Des Oulad Abdoun (Maroc) et Comparaison Avec Les Faunes Africaines Contemporaines: Systématique, Phylogénie et Paléobiogéographie. Unpublished PhD Thesis, Muséum National d'Histoire Naturelle, Paris, France.

Jouve, S. 2005. A new description of the skull of Dyrosaurus phosphaticus (Thomas, 1893) (Mesoeucrocodylia : Dyrosauridae) from the Lower Eocene of North Africa. Canadian Journal of Earth Sciences, 3:323337.

Jouve, S. 2009. The skull of Teleosaurus cadomensis (Crocodylomorpha; Thalattosuchia), and phylogenetic analysis of Thalattosuchia. Journal of Vertebrate Paleontology, 29:88-102.
Jouve, S. 2016. A new basal tomistomine (Crocodylia, Crocodyloidea) from Issel (Middle Eocene; France): palaeobiogeography of basal tomistomines and palaeogeographic consequences. Zoological Journal of the Linnean Society, 177:165-182.

Jouve, S., Bardet, N., Jalil, N.-E., Pereda Suberbiola, X., Bouya, B., and Amaghzaz, M. 2008a. The oldest African crocodylian: phylogeny, paleobiogeography, and differential survivorship of marine reptiles through the Cretaceous-Tertiary boundary. Journal of Vertebrate Paleontology, 28:409-421.

Jouve, S., Bouya, B., and Amaghzaz, M. 2005. A shortsnouted dyrosaurid (Crocodyliformes, Mesoeucrocodylia), from the Palaeocene of Morocco. Palaeontology, 48:359-369.

Jouve, S., Bouya, B., and Amaghzaz, M. 2008b. A longsnouted dyrosaurid (Crocodyliformes, Mesoeucrocodylia) from the Palaeocene of Morocco: phylogenetic and palaeobiogeographic implications. Palaeontology, 51:281-294.

Jouve, S., Bouya, B., Amaghzaz, M., and Meslouh, S. 2014. Maroccosuchus zennaroi (Crocodylia: Tomistominae) from the Eocene of Morocco: phylogenetic and palaeobiogeographical implications of the basalmost tomistomine. Journal of Systematic Palaeontology, 12:1-25.

Jouve, S., Mennecart, B., Douteau, J., and Jalil, N.-E. 2016. The oldest durophageous thalattosuchian (Crocodylomorpha, Thalattosuchia) from the lower Bathonian of Central High Atlas, Morocco. Palaeontology, 59:863-876.

Kelley, N.P., Motani, R., Jiang, D.-Y., Rieppel, O., and Schmitz, L. 2014. Selective extinction of Triassic marine reptiles during long-term sea-level changes illuminated by seawater strontium isotopes. Palaeogeography, Palaeoclimatology, Palaeoecology, 400:9-16.

Leuzinger, L., Kocsis, L., Billon-Bruyat, J.-P., Spezzaferri, S., and Vennemann, T. 2015. Stable isotope study of a new chondrichthyan fauna (Kimmeridgian, Porrentruy, Swiss Jura): an unusual freshwater-influenced isotopic composition for the hybodont shark Asteracanthus. Biogeosciences Discussions, 12:1289912921.

Lloyd, G.T. 2008. Generalized differencing of time series. http://www.graemetlloyd.com/methgd.html. Accessed 19 October 2015.

Lloyd, G.T., Young, J.R., and Smith, A.B. 2012. Taxonomic structure of the fossil record is shaped by sampling bias. Systematic Biology, 61:80-89.

Mannion, P.D., Benson, R.B.J., Carrano, M.T., Tennant, J.P., Judd, J., and Butler, R.J. 2015. Climate constrains the evolutionary history and biodiversity of crocodylians. Nature Communications, 6:8438.

Marsh, O.C. 1869. Notice of some new reptilian remains from the Cretaceous of Brazil. American Journal of Sciences and Arts, 47:1-3.

Martin, J.E., Amiot, R., Lécuyer, C., and Benton, M.J. 2014. Sea surface temperature contributes to marine 
crocodylomorph evolution. Nature Communications, 5. doi:10.1038/ncomms5658

Martin, J.E., Vincent, P., and Falconnet, J. 2015. The taxonomic content of Machimosaurus (Crocodylomorpha, Thalattosuchia). Comptes Rendus Palevol, 14:305-310.

Martin, J.E. and Vincent, P. 2013. New remains of Machimosaurus hugii von Meyer, 1837 (Crocodilia, Thalattosuchia) from the Kimmeridgian of Germany. Fossil Record, 16:179-196.

Miller, K.G., Kominz, M.A., Browning, J.V., Wright, J.D., Mountain, G., Katz, M.E., Sugarman, P.J., Cramer, B.S., Christie-Blick, N., and Pakar, S.F. 2005. The Phanerozoic record of global sea-level change. Science, 310:1293-1298.

Mueller-Töwe, I.J. 2005. Phylogenetic relationships of the Thalattosuchia. Zitteliana, 45:211-213.

Mueller-Töwe, I.J. 2006. Anatomy, Phylogeny, and Palaeoecology of the Basal Thalattosuchians (Mesoeucrocodylia) from the Liassic of Central Europe. Unpublished PhD thesis, Johannes Gutenberg-Universität, Bonn, Germany.

Pierce, S.E., Angielczyk, K.D., and Rayfield, E. J. 2009. Shape and mechanics in thalattosuchian (Crocodylomorpha) skulls: implications for feeding behaviour and niche partitioning. Journal of Anatomy, 215:555576.

Prokoph, A., Shields, G.A., and Veizer, J. 2008. Compilation and time-series analysis of a marine carbonate $\delta^{18} \mathrm{O}, \delta^{13} \mathrm{C}, 87 \mathrm{Sr} / 86 \mathrm{Sr}$ and $\delta^{34} \mathrm{~S}$ database through Earth history. Earth-Science Reviews, 87:113-133.

Purdy, E.G. 2008. Comparison of taxonomic diversity, strontium isotope and sea-level patterns. International Journal of Earth Sciences, 97:651-664.

$\mathrm{R}$ Core Team 2015. R: A language and environment for statistical computing. R Foundation for Statistical Computing, Vienna, Austria. URL https://www.R-project.org/.

Rook, D.L., Heim, N.A., and Marcot, J. 2013. Contrasting patterns and connections of rock and biotic diversity in the marine and non-marine fossil records of North America. Palaeogeography, Palaeoclimatology, Palaeoecology, 372:123-129.

Sauvage, H.E. 1874. Mémoire sur les dinosauriens et les crocodiliens des terrains jurassiques de Boulogne-
sur-Mer. Mémoires de la Société Géologique de France, 10:1-58.

Tennant, J.P., Mannion, P.D., and Upchurch, P. 2016. Environmental drivers of crocodyliform extinction across the Jurassic/Cretaceous transition. Proceedings of the Royal Society B: Biological Sciences, 283:20152840.

Vignaud, P. 1995. Les Thalattosuchia, Crocodiles Marins Du Mesozoique: Systématique Phylogénétique, Paléoécologie, Biochronologie et Implications Paléogéographiques. Unpublished PhD Thesis, Université de Poitiers, France.

Wilberg, E.W. 2012. Phylogenetic and Morphometric Assessment of the Evolution of the Longirostrine Crocodylomorphs. Unpublished PhD thesis, University of lowa, lowa City, USA.

Wilberg, E.W. 2015a. A new metriorhynchoid (Crocodylomorpha, Thalattosuchia) from the Middle Jurassic of Oregon and the evolutionary timing of marine adaptations in thalattosuchian crocodylomorphs. Journal of Vertebrate Paleontology, 35:e902846.

Wilberg, E.W. 2015b. What's in an outgroup? The impact of outgroup choice on the phylogenetic position of Thalattosuchia (Crocodylomorpha) and the origin of Crocodyliformes. Systematic Biology, 64:621-637.

Woods, H. 2010. Catalogue of the Type Fossils in the Woodwardian Museum. Cambridge University Press, Cambridge.

Young, M.T., Brusatte, S.L., De Andrade, M.B., Desojo, J.B., Beatty, B.L., Steel, L., Fernández, M.S., Sakamoto, M., Ruiz-Omeñaca, J.I., and Schoch, R.R. 2012. The cranial osteology and feeding ecology of the metriorhynchid crocodylomorph genera Dakosaurus and Plesiosuchus from the Late Jurassic of Europe. PLoS ONE, 7:e44985.

Young, M.T., Brusatte, S.L., Ruta, M., and De Andrade, M.B. 2010. The evolution of Metriorhynchoidea (Mesoeucrocodylia, Thalattosuchia): an integrated approach using geometric morphometrics, analysis of disparity, and biomechanics. Zoological Journal of the Linnean Society, 158:801-859.

Young, M.T., Hua, S., Steel, L., Foffa, D., Brusatte, S.L., Thuring, S., Mateus, O., Ruiz-Omenaca, J.I., Havlik, P., Lepage, Y., and De Andrade, M.B. 2014. Revision of the Late Jurassic teleosaurid genus Machimosaurus (Crocodylomorpha, Thalattosuchia). Royal Society Open Science, 1:140222. 


\section{APPENDIX 1.}

Species diversity data used in the correlation analyses, with various corrections: addition of the Moroccan machimosaurin, "Steneosaurus" cf. obtusidens (England), Machimosaurus rex, Anthracosuchus balrogus, and unidentified thalattosuchians (Sinemurian and Pliensbachian). In red are the corrected data. Species level. GL: ghost lineages.

All appendices are available online as one zipped file at palaeo-electronica.org/content/2017/ 1821-diversity-analysis-biases

\section{APPENDIX 2.}

Genera diversity data used in the correlation analyses, with various corrections: addition of the Moroccan machimosaurin, "Steneosaurus" cf. obtusidens (England), Machimosaurus rex, Anthracosuchus balrogus, and unidentified thalattosuchians (Sinemurian and Pliensbachian). In red are the corrected data. Genera level. GL: ghost lineages.

All appendices are available online as one zipped file at palaeo-electronica.org/content/2017/ 1821-diversity-analysis-biases

\section{APPENDIX 3.}

List of the crocodylomorph species considered in various diversity analyses (present work; Martin et al., 2014; Mannion et al., 2015; Tennant et al., 2016). The analyses considered the Hettangian-Rupelian time interval, except Tennant et al. (2016) who used the Jurassic-Cretaceous interval (Hettangian-Maastrichtian).

All appendices are available online as one zipped file at palaeo-electronica.org/content/2017/ 1821-diversity-analysis-biases

\section{APPENDIX 4.}

Table of the values used to construct the graphs of the Figures 2 and 3. Number of crocodylomorph species and genera considered in various diversity analyses (present work; Martin et al., 2014; Mannion et al., 2015; Tennant et al., 2016). All the analyses considered the HettangianRupelian time interval, except Tennant et al. (2016) who used the Jurassic-Cretaceous interval (Hettangian-Maastrichtian).

All appendices are available online as one zipped file at palaeo-electronica.org/content/2017/ 1821-diversity-analysis-biases

\section{APPENDIX 5.}

Data used to calculate the sea surface temperature polynomial curve. The theoretical values are obtained in OpenOffice 4 with the add-on CorelPolyGUI (Gutman et al., 2012).

All appendices are available online as one zipped file at palaeo-electronica.org/content/2017/ 1821-diversity-analysis-biases 


\section{APPENDIX 6.}

Data used in correlation analyses: uncorrected diversity, phylogenetically corrected diversity, logarithm, time-corrected (divided by duration of time bin), and generalized-differenced data, sea surface temperature (Martin et al., 2014), sea level (Haq et al., 1987; Miller et al., 2005), sea surface temperature from polynomial curve, sea surface temperature from three-point moving average, sea surface temperature from smoothing spline, sea surface temperature from weighted three-point moving average.

All appendices are available online as one zipped file at palaeo-electronica.org/content/2017/ 1821-diversity-analysis-biases

\section{APPENDIX 7.}

Complete result for the calculated correlations between marine crocodylomorph diversity (metriorhynchoids excluded) with the sea surface temperature (Martin et al., 2014), the sea level from Haq et al. (1987) and Miller et al. (2005) for several time intervals (Hettangian-Rupelian; Pliensbachian-Rupelian; Toarcian-Priabonian). Comparison between the results obtained with the original data (Martin et al., 2014) (in blue) and the original data + the new material and species (in red).

All appendices are available online as one zipped file at palaeo-electronica.org/content/2017/ 1821-diversity-analysis-biases

\section{APPENDIX 8.}

Complete result for the calculated correlations between marine crocodylomorph diversity (metriorhynchoids excluded) with the sea surface temperature (Martin et al., 2014), the sea level from Haq et al. (1987) and Miller et al. (2005) for several time intervals (Hettangian-Rupelian; Pliensbachian-Rupelian; Toarcian-Priabonian). Comparison between the results obtained with the original data (Martin et al., 2014) + unidentified thalattosuchians + ghost lineage (in blue) and the original data (Martin et al., 2014) + unidentified thalattosuchians + ghost lineage + new material + taxonomic corrections (in red).

All appendices are available online as one zipped file at palaeo-electronica.org/content/2017/ 1821-diversity-analysis-biases

\section{APPENDIX 9.}

Complete result for the calculated correlations between the teleosauroid diversity with the sea surface temperature (Martin et al., 2014), the sea level from Haq et al. (1987) and Miller et al. (2005) for several time intervals (Hettangian-Berriasian; Pliensbachian-Berriasian). Comparison between the results obtained with the original data (Martin et al., 2014) (in blue), the original data (Martin et al., 2014) + the new material and species (in red), the original data (Martin et al., 2014) + unidentified thalattosuchians + ghost lineage (in blue), and the original data + unidentified thalattosuchians + ghost lineage + taxonomical corrections + new material and species (in red). All appendices are available online as one zipped file at palaeo-electronica.org/content/2017/ 1821-diversity-analysis-biases

\section{APPENDIX 10.}

Complete result for the calculated correlations between marine crocodylomorph diversity (metriorhynchoids excluded) with the sea surface temperature (Martin et al., 2014) from polynomial curve. Comparison between the results obtained with the original data (Martin et al., 2014) (in blue) and the original data + the new material and species (in red).

All appendices are available online as one zipped file at palaeo-electronica.org/content/2017/ 1821-diversity-analysis-biases 


\section{APPENDIX 11.}

Complete result for the calculated correlations between marine crocodylomorph diversity (metriorhynchoids excluded) with the sea surface temperature (Martin et al., 2014) from polynomial curve. Comparison between the results obtained with the original data (Martin et al., 2014) + unidentified thalattosuchians + ghost lineage (in blue) and the original data (Martin et al., 2014) + unidentified thalattosuchians + ghost lineage + new material + taxonomic corrections (in red). All appendices are available online as one zipped file at palaeo-electronica.org/content/2017/ 1821-diversity-analysis-biases

\section{APPENDIX 12.}

Complete result for the calculated correlations between the teleosauroid diversity with the polynomial curve of the sea surface temperature (Martin et al., 2014) for two time intervals: Hettangian-Berriasian and Hettangian-Barremian. Comparison between the results obtained with the original data (Martin et al., 2014) (in blue), the original data (Martin et al., 2014) + new material and species (in red), the original data (Martin et al., 2014) + unidentified thalattosuchians + ghost lineage (in blue), and the original data (Martin et al. 2014) + unidentified thalattosuchians + ghost lineage + new material + taxonomic corrections (in red).

All appendices are available online as one zipped file at palaeo-electronica.org/content/2017/ 1821-diversity-analysis-biases

\section{APPENDIX 13.}

Complete result for the calculated correlations between marine crocodylomorph diversity (metriorhynchoids excluded) with the sea surface temperature (Martin et al., 2014) from three-point moving average. Comparison between the results obtained with the original data (Martin et al., 2014) (in blue) and the original data + the new material and species (in red).

All appendices are available online as one zipped file at palaeo-electronica.org/content/2017/ 1821-diversity-analysis-biases

\section{APPENDIX 14.}

Complete result for the calculated correlations between marine crocodylomorph diversity (metriorhynchoids excluded) with the sea surface temperature (Martin et al., 2014) from three-point moving average. Comparison between the results obtained with the original data (Martin et al., $2014)+$ unidentified thalattosuchians + ghost lineage (in blue), and the original data (Martin et al., 2014) + unidentified thalattosuchians + ghost lineage + new material and species + taxonomic corrections (in red).

All appendices are available online as one zipped file at palaeo-electronica.org/content/2017/ 1821-diversity-analysis-biases

\section{APPENDIX 15.}

Complete result for the calculated correlations between the teleosauroid diversity with the threepoint moving average of the sea surface temperature (Martin et al., 2014) for two time intervals: Hettangian-Berriasian and Hettangian-Barremian. Comparison between the results obtained with the original data (Martin et al., 2014) (in blue), the original data (Martin et al., 2014) + new material and species (in red), the original data (Martin et al., 2014) + unidentified thalattosuchians + ghost lineage (in blue) and the original data (Martin et al., 2014) + unidentified thalattosuchians + ghost lineage + new material and species + taxonomic corrections (in red).

All appendices are available online as one zipped file at palaeo-electronica.org/content/2017/ 1821-diversity-analysis-biases 


\section{APPENDIX 16.}

Complete result for the calculated correlations between marine crocodylomorph diversity (metriorhynchoids excluded) with the sea surface temperature (Martin et al., 2014) from smoothing spline. Comparison between the results obtained with the original data (Martin et al., 2014) (in blue) and the original data + the new material and species (in red).

All appendices are available online as one zipped file at palaeo-electronica.org/content/2017/ 1821-diversity-analysis-biases

\section{APPENDIX 17.}

Complete result for the calculated correlations between marine crocodylomorph diversity (metriorhynchoids excluded) with the sea surface temperature (Martin et al., 2014) from smoothing spline. Comparison between the results obtained with the original data (Martin et al., 2014) + unidentified thalattosuchians + ghost lineage (in blue), and the original data (Martin et al., 2014) + unidentified thalattosuchians + ghost lineage + new material + taxonomic corrections (in red). All appendices are available online as one zipped file at palaeo-electronica.org/content/2017/ 1821-diversity-analysis-biases

\section{APPENDIX 18.}

Complete result for the calculated correlations between the teleosauroid diversity with the smoothing spline of the sea surface temperature (Martin et al., 2014) for two time intervals: Hettangian-Berriasian and Hettangian-Barremian. Comparison between the results obtained with the original data (Martin et al., 2014) (in blue), the original data (Martin et al., 2014) + new material and species (in red), the original data (Martin et al., 2014) + unidentified thalattosuchians + ghost lineage (in blue) and the original data (Martin et al., 2014) + unidentified thalattosuchians + ghost lineage + new material and species + taxonomic corrections (in red).

All appendices are available online as one zipped file at palaeo-electronica.org/content/2017/ 1821-diversity-analysis-biases

\section{APPENDIX 19.}

Complete result for the calculated correlations between marine crocodylomorph diversity (metriorhynchoids excluded) with the sea surface temperature (Martin et al., 2014) from weighted three-point moving average. Comparison between the results obtained with the original data (Martin et al., 2014) (in blue) and the original data + the new material and species (in red).

All appendices are available online as one zipped file at palaeo-electronica.org/content/2017/ 1821-diversity-analysis-biases

\section{APPENDIX 20.}

Complete result for the calculated correlations between marine crocodylomorph diversity (metriorhynchoids excluded) with the sea surface temperature (Martin et al., 2014) from weighted three-point moving average. Comparison between the results obtained with the original data (Martin et al., 2014) + unidentified thalattosuchians + ghost lineage (in blue), and the original data (Martin et al., 2014) + unidentified thalattosuchians + ghost lineage + new material + taxonomic corrections (in red).

All appendices are available online as one zipped file at palaeo-electronica.org/content/2017/ 1821-diversity-analysis-biases 


\section{APPENDIX 21.}

Complete result for the calculated correlations between the teleosauroid diversity with the weighted three-point moving average of the sea surface temperature (Martin et al., 2014) for two time intervals: Hettangian-Berriasian and Hettangian-Barremian. Comparison between the results obtained with the original data (Martin et al., 2014) + unidentified thalattosuchians + ghost lineage (in blue), and the original data (Martin et al., 2014) + unidentified thalattosuchians + ghost lineage + new material + taxonomic corrections (in red).

All appendices are available online as one zipped file at palaeo-electronica.org/content/2017/ 1821-diversity-analysis-biases 